\title{
Time-frequency analysis of acoustic emission signals generated by cement-fiber boards during bending test
}

\author{
Anna Adamczak-Bugno, , Grzegorz Świt, and Aleksandra Krampikowska \\ Kielce University of Technology, Faculty of Civil Engineering and Architecture, Aleja Tysiąclecia \\ Państwa Polskiego 7, Poland
}

\begin{abstract}
Fiber-cement building materials have been used in civil engineering for over one hundred years. Contemporary fiber-cement boards are made of natural raw materials such as cement, cellulose fibers, PVA and water. Materials made of fiber-cement are used in construction as a building and finishing material for elevations, internal walls and roofs, hence are exposed to environmental conditions such as rainfall and temperature changes, in particular, frequent temperature transition through $0^{\circ} \mathrm{C}$ in a 24 hour cycle (cyclic freezing-thawing). In addition, fibrous cement materials, primarily used as cladding elements, are exposed to exceptional conditions, which include the high temperature caused by fire. The article presents the results of experimental tests of bending strength of cement-fiber boards subjected to environmental factors and exceptional factors. The paper also presents a proposal to use a non-destructive method of acoustic emission (AE) based on time-frequency analysis for testing fiber-cement boards. Interesting research results were obtained, which allowed to trace the differences in the mechanisms of material destruction under the influence of various factors.
\end{abstract}

\section{Introduction}

Fibre-cement is commonly used in the construction industry as building and finishing material in the form of roof boards, facade panels and internal boards. Fibre-cement boards are made of, among others, cement, cellulose fibres and of polyvinyl alcohol (PVA). Their composition also includes water and fillers such as, for example, limestone. A major part (more than 50\%) of the production mixture is cement, responsible for binding the material and its final durability. Cellulose is a reinforcement and a filler, as well as an addition that ensures that there is appropriate amount of water in the process of binding the cement. On the other hand, PVA fibres are used as structural reinforcement of fibrecement boards that provides them with specific strength [1-2]. Fibre-cement boards used on facades and roof surfaces are exposed to production flaws because of incorrect mixing of the ingredients, development or occurrence of air cells that causes thinning of nominal thickness [3-5]. Moreover, the influence of environmental factors, such as changes

\footnotetext{
* Corresponding author: aadamczak@tu.kielce.pl
} 
of temperature, rainfalls, snow, and so on, may cause ageing of the product and creation of micro-cracks. In relation to this, it is significant to determine how production and exploitation losses influence the designed functionality, durability and the level of usage of the products made on the basis of fibre-cement. So far, the research on the material of fibre-cement boards has been limited to determining standard physical and mechanical parameters in newly produced materials [6]. However, there is no research on the influence of time on the strength of these elements. It may be caused by the fact that this material in its current form has been used in the construction industry for relatively short period of time. However, it should be noted that the exposition of calcareous phases of cement matrix to the influence of carbon dioxide causes carbonatation of the matrix. At the beginning of the work of these materials, this phenomenon has a positive influence on the material, it improves the quality of bonds between the layers of the material. However, after a few years, the level of bond between the layers starts to decrease because of stresses caused by temperature and dampness. Although carbonatation initially has a positive influence on the bonds between the phases, the reactions of carbon with the products of hydration contribute to the movement of dampness in the material, and this finally leads to delamination of the matrix. It is, of course, a long process. However, its effect is that the strength of the material decreases by even $40 \%$ after 10 years of being exposed to the influence of environment [7].

Fibre-cement boards available on the market are characterised by two main types of external surfaces. They may have the structure of raw fibre-cement or they may be covered with layers of acrylic coatings. However, even when additional protective coatings are used, there is risk of exposing the matrix and fibres to the influence of external conditions. In the case of incorrect instalment of the board on the framework, the boards are easily damaged, there are visible chips on their surface. However, attention to proper priming of uncovered places is rarely paid, so these places create trails for penetration of moisture and for damage caused by cyclical freezing-thawing. Although these are small areas, the unprotected surfaces may significantly decrease the general durability of the material, even when there is no extreme dampness or other harmful factors.

In the literature, there are results of research on fibre-cement elements with the use of non-destructive methods, such as ultrasonic method. Therefore, there is a possibility to use other method of non-destructive tests in order to develop the knowledge of this phenomenon and to compare the results [8-11]. Such comparison allows to determinate which techniques of non-destructive tests will confirm the results and reasonability of their usage.

For materials testing, including composite materials, a method of acoustic emission (AE) is useful, which consists in recording elastic waves resulting from changes on micro- or macro-structural level of the material as a result of imposing external stimulus (load, the activity of external environment, etc.) in real time [12-15]. AE method is a developing and widely applied diagnostic, non-destructive testing method (NDT) [16-18]. Recently, there has also been an increase in interest in methods based on time-frequency spectrum analysis as a tool for material research, including composite materials [19, 24].

\section{Materials and methods}

\subsection{Materials}

The tests were carried out on two series of fibre-cement materials, marked as PZBS and PZBW. The samples that were tested were cut from fibre-cement board measuring $3.1 \times 1.25 \mathrm{~m}$. The dimensions of tested elements were 300x50x8 mm. Samples marked with PZBS were in air-dry state. The PZBW letters mean that the samples, before the test was conducted, were subject to heat treatment - they were burnt in laboratory furnace for 3 hours 
in the temperature of $230^{\circ} \mathrm{C}$. As the result of the heat treatment, cellulose fibres and PVA fibres were destroyed (burnt). 5 samples of each series were subject to the tests.

Three-point bending test was carried out with the use of Zwick-Roell testing machine located at Kielce University of Technology. Bending speed was $0.2 \mathrm{~mm} / \mathrm{min}$.

Table 1. Comparison of tested board.

\begin{tabular}{|c|c|}
\hline Properties & $\begin{array}{c}\text { Values for } \\
\text { samples from series PZBS/PZBW }\end{array}$ \\
\hline $\begin{array}{c}\text { Density } \\
{[\mathrm{g} / \mathrm{cm} 3]}\end{array}$ & $>1,6524$ \\
\hline $\begin{array}{c}\text { Porosity } \\
{[\%]}\end{array}$ & $>18$ \\
\hline $\begin{array}{c}\text { Thermal } \\
\text { properties }\end{array}$ & No danger of ignition or spread of fire \\
\hline $\begin{array}{c}\text { Way of } \\
\text { application }\end{array}$ & $\begin{array}{c}\text { Elevation: external wall cladding, } \\
\text { balcony panels, railings, balustrades }\end{array}$ \\
\hline
\end{tabular}

For the acquisition of acoustic emission signals, Vallen AMSY-5 measuring apparatus was used. Two broadband sensors were used, and they were mounted with a clamp on the central part of the sample. A layer of resin was applied on the surface of the contact. The accuracy of operation of apparatus was checked before carrying out the proper measurement. In the vicinity of each sensor, signals for testing the efficiency of the sensors and the correctness of their mounting were initiated. The source of those signals was graphite that was being broken, its diameter was $0.5 \mathrm{~mm}$ and it was made by Pentel company. It was stated that each sensor recorded AE signals with the amplitude of about $98 \mathrm{~dB}$.

Figure 1 presents the view of testing station of three-point bending with the tested element, on which the AE sensors were installed.

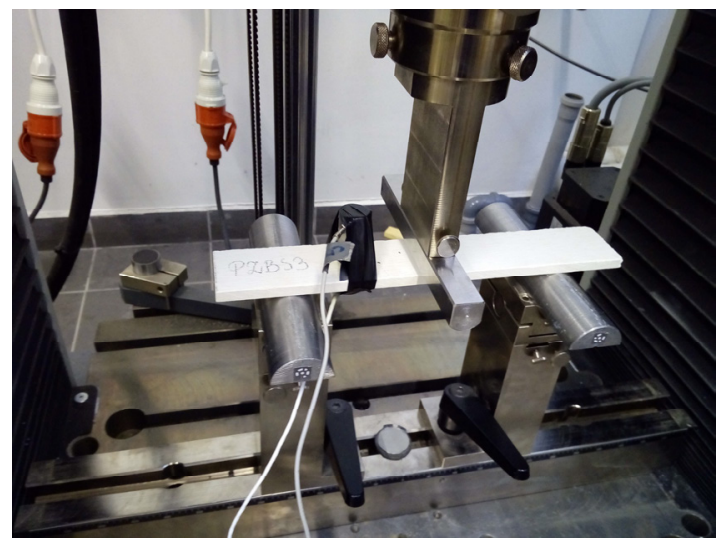

Fig. 1. View of the test bench.

\subsection{Methods}

Programs analysing measurement data used by Vallen company are based mainly on waves analysis, using fast Fourier transform and wavelet analysis (time-frequency analysis). The basic technique of frequency analysis is Fourier transform. The disadvantage of this method is the lack of the possibility to determine the time of occurrence of effects caused by local non-stationarities of the signal. Gabor transform, which is the modification of Fourier transform, allowed to partially remove this inconvenience. On the other hand, Short Time 
Fourier Transform (STFT) is the generalisation of Gabor transform, and it can be formulated as follows [25]:

$$
S(b, f)=\int_{-\infty}^{+\infty} x(t) \cdot e^{-j 2 \pi f} \cdot w(t-b) d t
$$

In this transform, a localisation window $w(t-b)$ was implemented, in which thanks to the $b$ parameter it is possible to replace the window in time domain. The function of the window can be any function which meets specific conditions. However, this window, because of its permanent width, turned out to be ineffective in the analysis of signals that simultaneously consist of components characterised by low and high frequencies.

As a result of implementing an additional scale parameter $a$ to localisation window in Gabor transform, a continuous wavelet transform was developed. An analysis function, $\Psi((t-b) / a)$, called a main wavelet, has a scale factor $a$, which causes the change of duration of a wavelet and the moving factor $b$, which changes the position of the wavelet on time axis. The equation therefore represents a band-pass filtration of the signal with the use of filters of different passbands.

Wavelet transform (WT) is the following dual function:

$$
W T(a, b)=\frac{1}{\sqrt{a}} \int_{-\infty}^{+\infty} x(t) \cdot \Psi\left(\frac{t-b}{a}\right) d t, a, b \in R, a \neq 0
$$

The basic advantage of wavelet transform is the possibility to select resolution in the domain of frequency and time. The modulus of wavelet transform of the signal is the representation of the changes of vibration energy in the time and frequency function.

The wavelet theory has been arousing the interest of both mathematicians and engineers for several years. Additionally, apart from time-frequency analysis, it is commonly applied in the fields of, among others, speech analysis, images recognition and it improves the quality of recordings [26,27].

\section{Results}

Figures 2 and 3 present examples of record of the number of counts in time function together with the increase of force graph, respectively for the tested samples: PZBS and PZBW. Figures 4 and 5 present the graphs of energy of events in the time function for two types of samples that were tested. In turn, Figure 6 shows views of damaged samples of the PZBS and PZBW series. In Table 2 and Table 3 characteristics of AE signals for each sample PZBS and PZBW series are shows.

When analysing figures 2-5, a significant difference in the process of destruction of the tested samples of PZBS and PZBW series may be noticed. It is clearly visible that heat treatment significantly influences the character of recording the number of counts of $\mathrm{AE}$ and the AE events energy. In the case of the samples of the PZBS series, there is little acoustic activity in almost the entire process. It is only at the moment of destruction of the sample that there is a significant increase of both the number of counts and the energy of acoustic emission events. It may be also observed that in the samples in air-dry state, the counts of $\mathrm{AE}$ recorded after reaching maximum level of load are not related to significant level of energy of the signals. It is assumed that the activity of AE occurring after reaching $\mathrm{F}_{\max }$ is generated by breakdown of fibres bundle. In the tensiled area of the tested samples, there is a crack occurring across their entire width (Fig. 6a). In the case of the PZBW series, there are three main stages of acoustic activity before the moment of destruction: the first one without a stress micro-crack evolution, the second one with the brittle damage evolution in micro-scale and the third one with the macro-crack formation connected with the sudden destruction of the sample. It is thought that this fact is related with the phenomenon of brittle 
fracturing of the matrix. At the moment of destruction of the burnt samples, there is rapid increase of the recorded descriptors. The destruction occurs immediately after reaching Fmax, and the sample itself breaks into two parts in the place of force application (Fig. 6b).

The way of destruction of the samples shown in Fig. 6 clearly defines the role of fibres used in this case from the point of view of strength of materials. When the fibres were present in the virgin material structure of boards, shearing was responsible for the exhaustion of load capacity of the board. When the fibres were burnt out, the board was destroyed by bending.

Analyzing the results presented in Table 2, the average value of bending force at the level of $0.393 \mathrm{kN}$, the average value of total number of AE counts at the level of 9496, the average value of maximal energy of $A E$ events at the level of $6.113 \mathrm{e}^{8}$ were determined.

In turn, analyzing the results presented in Table 3, the average value of bending force at the level of $0.259 \mathrm{kN}$, the average value of the total number of counts at the level of 4118 and the average value of the AE maximal energy of AE events at the level of $7.758 \mathrm{e}^{8}$ were determined.

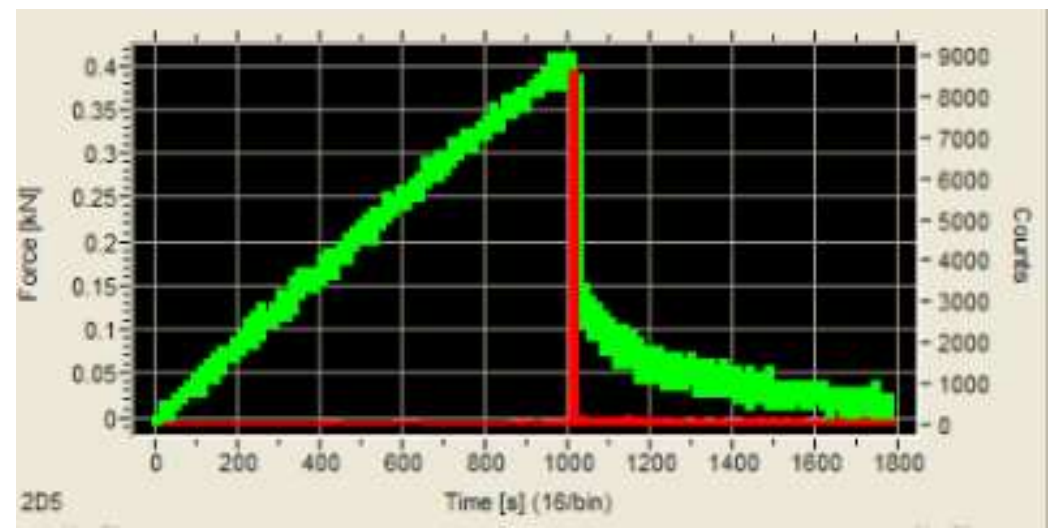

Fig. 2. Record of counts as a function of time along with a plot of force increment for a sample from the PZBS series.

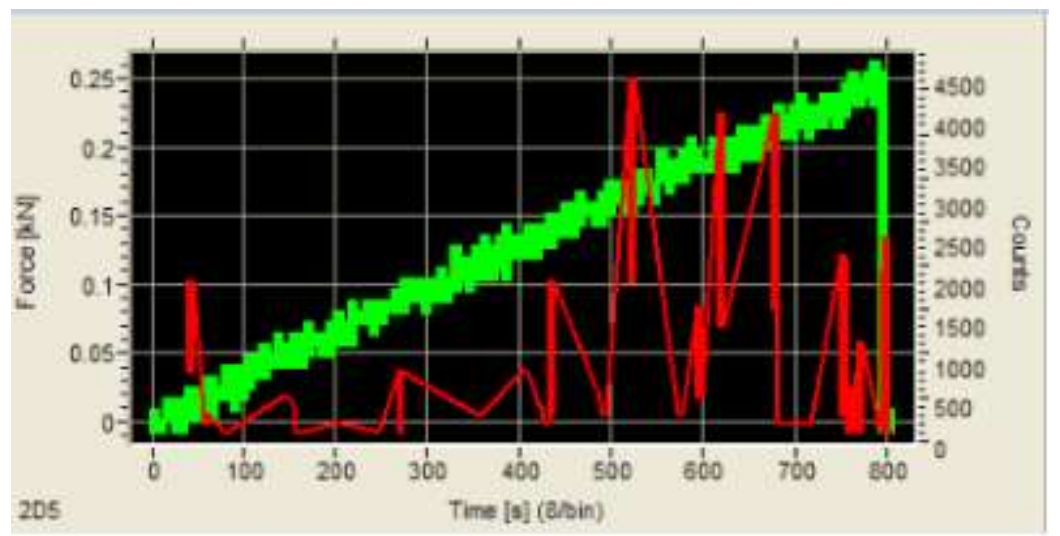

Fig. 3. Record of counts as a function of time along with a plot of force increment for a sample from the PZBS series. 


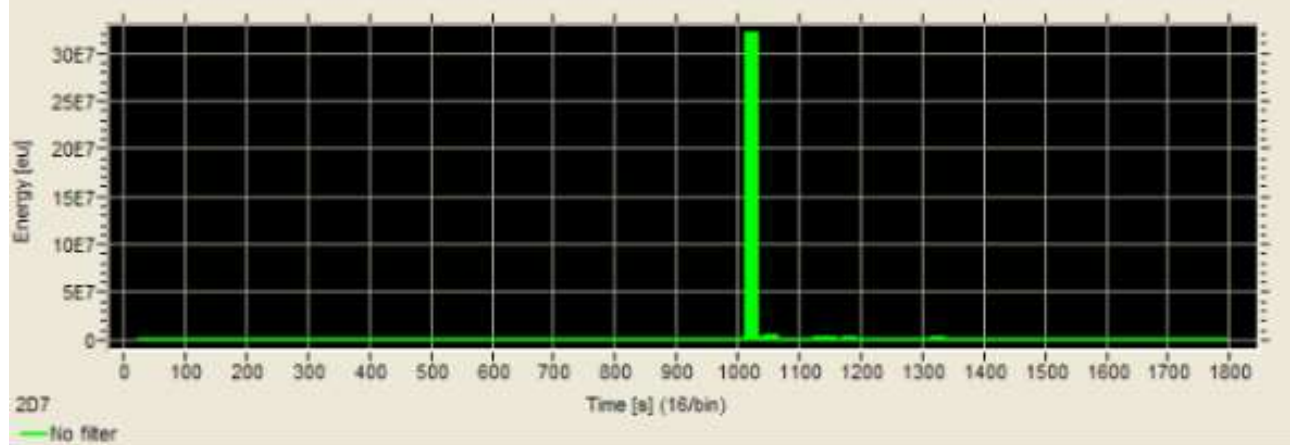

Fig. 4. Graph of energy of events in the time function for a sample of the PZBS series.

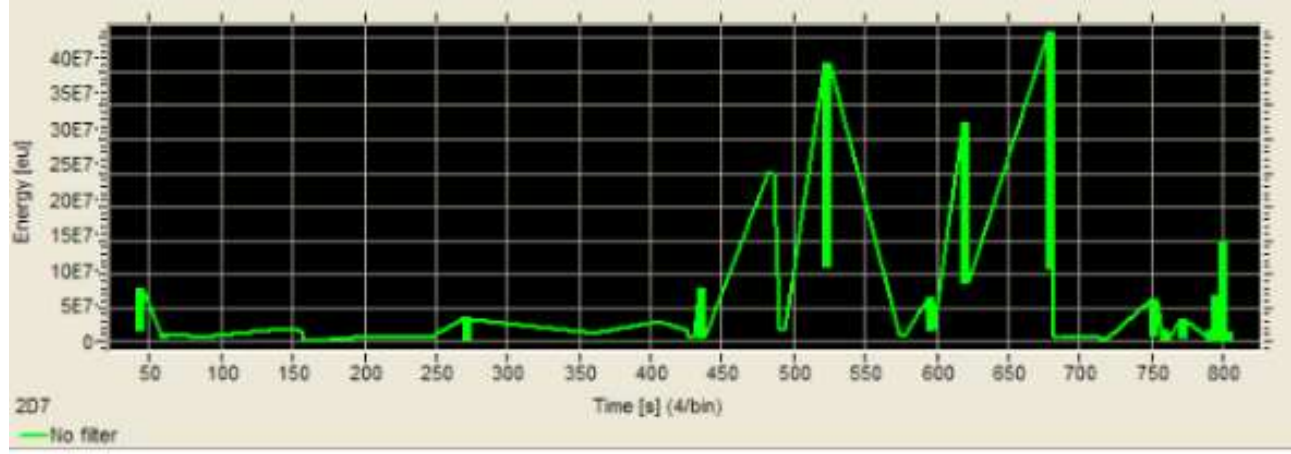

Fig. 5. Graph of energy of events in the time function for a sample of the PZBW series.

a)

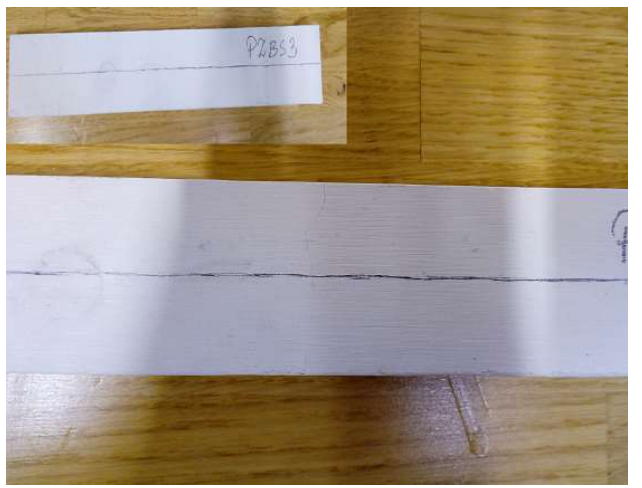

b)

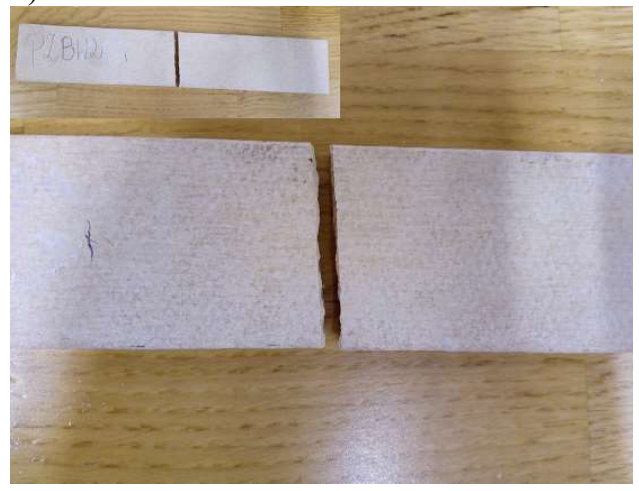

Fig. 6. View of the destroyed samples a) for the sample from the PZBS series b) for the sample from the PZBW series. 
Table 2. The characteristics of AE signals for each sample PZBS series.

\begin{tabular}{|c|c|c|c|c|c|}
\hline $\begin{array}{c}\text { Symbol of } \\
\text { board }\end{array}$ & PZBS1 & PZBS2 & PZBS3 & PZBS4 & PZBS5 \\
\hline $\begin{array}{c}\text { Maximal } \\
\text { load } \\
{[\mathrm{kN}]}\end{array}$ & 0,355 & 0,411 & 0,403 & 0,387 & 0,410 \\
\hline $\begin{array}{c}\text { Character of } \\
\text { destruction }\end{array}$ & \multicolumn{2}{|c|}{ destroyed by shearing of fibers (crack occurring across entire width) } \\
\hline $\begin{array}{c}\text { Total } \\
\text { number of } \\
\text { AE counts }\end{array}$ & 7681 & 8994 & 12093 & 8456 & 10259 \\
\hline $\begin{array}{c}\text { Maximal } \\
\text { energy of } \\
\text { AE events } \\
{[\mathrm{eu}]}\end{array}$ & $9.133 \mathrm{e}^{8}$ & $3.199 \mathrm{e}^{8}$ & $6.070 \mathrm{e}^{8}$ & $8.017 \mathrm{e}^{8}$ & $4.147 \mathrm{e}^{8}$ \\
\hline
\end{tabular}

Table 3. The characteristics of AE signals for each sample PZBS series.

\begin{tabular}{|c|c|c|c|c|c|}
\hline $\begin{array}{c}\text { Symbol of } \\
\text { board }\end{array}$ & PZBW1 & PZBW2 & PZBW3 & PZBW4 & PZBW5 \\
\hline $\begin{array}{c}\text { Maximal } \\
\text { load } \\
{[\mathrm{kN}]}\end{array}$ & 0,261 & 0,237 & 0,261 & 0,292 & 0,242 \\
\hline $\begin{array}{c}\text { Character of } \\
\text { destruction }\end{array}$ & \multicolumn{5}{|c|}{ brittle cracking across the entire width } \\
\hline $\begin{array}{c}\text { Total } \\
\text { number of } \\
\text { AE counts }\end{array}$ & 4302 & 3418 & 4365 & 4531 & 3974 \\
\hline $\begin{array}{c}\text { Maximal } \\
\text { energy of } \\
\text { AE events } \\
\text { [eu] }\end{array}$ & $6.238 \mathrm{e}^{8}$ & $8.596 \mathrm{e}^{8}$ & $4.319 \mathrm{e}^{8}$ & $1.432 \mathrm{e}^{9}$ & $5.318 \mathrm{e}^{8}$ \\
\hline
\end{tabular}

Using the Vallen Wavelet module, dedicated to the Vallen AMSY-5 software, frequency spectrum of the signal graphs were made for the exemplary sample of the PZBS series (Fig. 7) and the PZBW series (Fig. 8) at the moment of destruction. When analysing the presented graphs, it may be noticed that in the case of the sample of the PZBS series, the culminant amplitudes occur for the frequencies between 30 and $90 \mathrm{kHz}$. For the remaining range of the frequencies, the spectrum characteristics is almost flat. In relation to that, the entire frequency spectrum was classified as caused by the rupture of reinforcement. In the case of the sample of the PZBW series, characteristic peaks occurring for the frequencies from the range between 40 and $300 \mathrm{kHz}$ were classified as the form of events caused by brittle fracturing of the matrix.

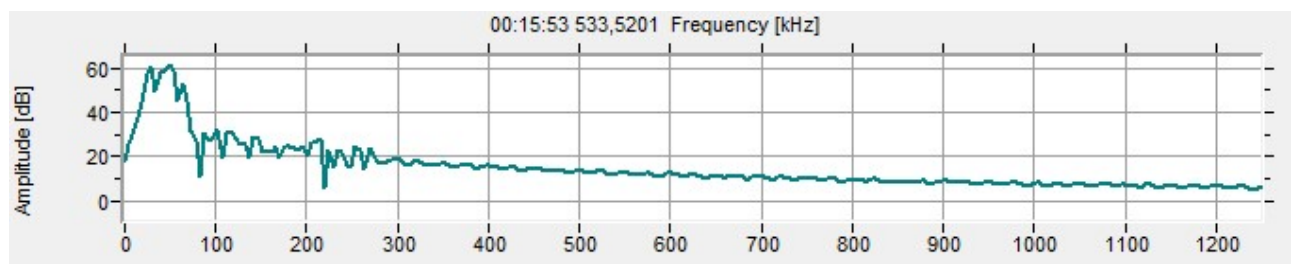

Fig. 7. Frequency spectrum of the sample signal of the PZBS series. 


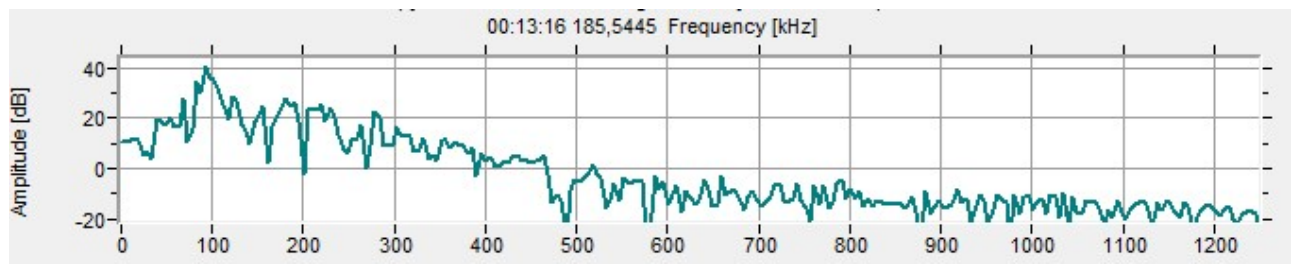

Fig. 8. Frequency spectrum of the sample signal of the PZBW series.

The evaluation of AE signals of the tested tapes was also carried out in time-frequency domain, by determining three-dimensional spectrograms of spectral density. In these figures, the "a" symbol shows the results of the analysis of AE signals generated by one of the samples of the PZBS series at the moment of destruction, and the "b" symbol shows the results of the analysis of the signals generated by one of the samples of the PZBW series at the moment of destruction.

Figure 9 shows spectrograms of spectral density of AE signals generated by the analysed samples of fibre-cement boards.

On these spectrograms of spectral density, time-frequency structures differing in dominant frequency bands can be seen. On figure $9 \mathrm{a}$, the dominant frequency band is included in the range of $5-100 \mathrm{kHz}$, and on figure $9 \mathrm{~b}$, in the range of $30-500 \mathrm{kHz}$. The biggest amplitude is in the case of the structures that occur at the beginning of the analysed run in the case of $8 \mathrm{a}$, and at the end of the time span in the case of $9 \mathrm{~b}$. Frequency components between $25 \mathrm{kHz}$ and $60 \mathrm{kHz}$ for the sample of the PZBS series have the highest values of amplitudes. For the sample of the PZBW series, the biggest values of amplitudes were noticed for the frequency components from $75 \mathrm{kHz}$ to $125 \mathrm{kHz}$. The analysis of the measurement results also proved that the signals corresponding to the activity of the sample of the PZBW series have time-frequency structures of the highest amplitudes (Fig. 9b). On the basis of spectrograms analysis, determined for AE signals generated by one of the samples that were subject to high temperature (Fig. 9b), it was stated that explicit differences in their time-frequency structure occur. It was noticed that there was a substantial delamination of the acoustic structure of the analysed AE signal, as well as different distribution of particular frequency structures in time.

The occurrence of a clear separation of the spectrum of the signal in the time-frequency domain shown in Fig. 9 for PZBW sample is probably related to two groups of initial crack widths present in the material structure before loading: technological ones together with those induced by heating and bigger voids left after burnt fibers.

a)

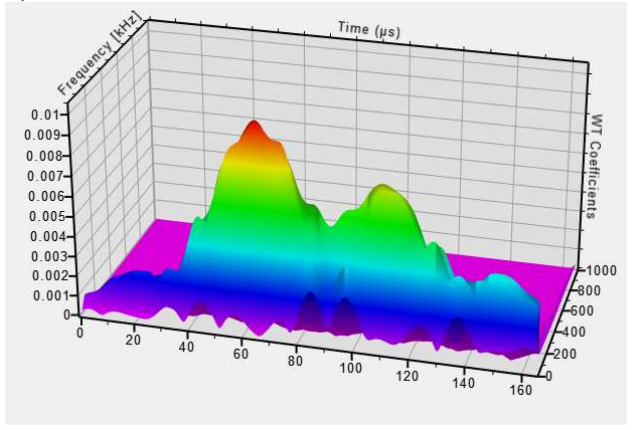

b)

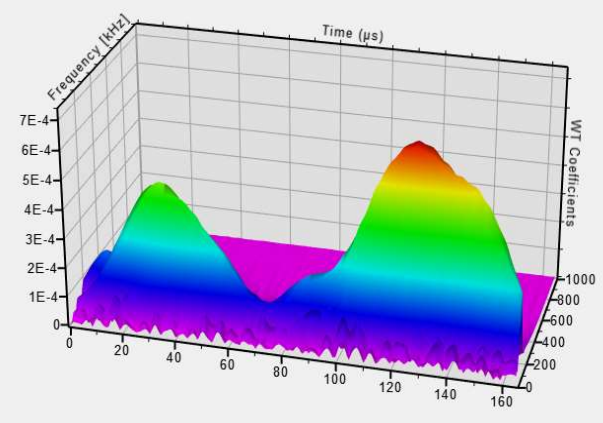

Fig. 9. Three-dimensional spectrograms of spectral density of EA signals generated during bending of cement-fiber board samples a) for the sample from the PZBS series b) for the sample from the PZBW series. 


\section{Conclusions}

The article presents the proposal for the application of non-destructive method of acoustic emission and time-frequency analysis for analysing fibre-cement boards. The research was conducted on two series of samples, and they were cut from fibre-cement board that is available on the market. During the research, the results that were obtained allowed to distinguish the process of destruction of the fibres that are included in the material from the process of destruction of the matrix itself.

It was also justified that there is necessity to control the condition of composite material on account of determining the conditions of safe exploitation of the construction. For this purpose, the methods of non-destructive testing (NDT) can be used, and they allow to determine the state of the material in a periodic or continuous manner in real time. On the basis of the results presented in the article, it can be stated that with the application of modern methods of digital image processing in the domain of time and in the time-frequency domain, there is a possibility to use the acoustic emission method to evaluate the condition of fibrecement boards.

The results of the research allowed to observe changes that occur in the material when it is under load. According to the authors, this method shows the possibility to be used from the point of view of the construction. In accordance to that, it should be further developed in the context of diagnosing fibre-cement materials.

\section{References}

1. Information from the website: http://www.euronit.de/

2. Information from the website: http://www.cembrit.com/

3. T. Gorzelańczyk, K. Schabowicz, Building Materials (in Polish) 10 (2015)

4. T. Gorzelańczyk, K. Schabowicz, Revitalization of building facades using fiber-cement boards Building Materials (in Polish) 11 (2015)

5. K. Schabowicz, T. Gorzelańczyk, M. Szymków, Murator (in Polish) 6 (2017)

6. PN-EN 12467:2013-03E - Fibre-cement flat sheets - Product specification and test methods

7. A. M.Cooke, 7th Inorganic-Bonded Wood and Fiber Conference (2000)

8. R. Drelich, T. Gorzelańczyk, M. Pakuła, K. Schabowicz, Automation in Constr. 57 (2015)

9. T. Gorzelańczyk, K. Schabowicz, M. Szymków, Welding Technology Review (in Polish) 88(10) 2016

10. T. Gorzelańczyk, K. Schabowicz, 11th European Conference on Non-Destructive Testing (2014)

11. A. Adamczak Bugno, T. Gorzelańczyk, A. Krampikowska, M. Szymków, Nondesctruc tive Testing and Diagnostics (in Polish) 3 (2017)

12. D. G. Aggelis, Mechanics Research Communications 38(3) (2011)

13. D. G. Aggelis, D. V. Soulioti, N. Sapouridis, N. M. Barkoula, A.S. Paipetis, T. E. Matikas, Construction and Building Materials 25(11) (2011)

14. M. Ardanuy, J. Claramunt, R. D. Toledo Filho, Construction and Building Materials 79 (2015)

15. Y. Chen, D. Bloomquist, R. Crowley, Applied Mechanics and Materials 239-240 (2013)

16. B. Goszczyńska, G. Świt, W. Trąmpczyński, 7th International Conference on Bridge Maintenance Safety and Management (IABMAS) (2014) 
17. B. Goszczyńska, G. Świt, W. Trąmpczyński, A. Krampikowska, J. Tworzewska, P. Tworzewski, Archives Of Civil And Mechanical Engineer 12(1) (2012)

18. B. Goszczyńska, G. Świt, W. Trąmpczyński, Bulletin of the Polish Academy of Sciences: Technical Sciences 63(1) (2015)

19. G. Świt, P. Olaszek, J. Casas, Bridge Maintenance, Safety, Management And Life-Cycle Optimization (2010)

20. G. Świt, Journal of Materials in Civil Engineering 16(5) (2004)

21. G. Świt, A. Krampikowska, M. Chinh Luong, Proceedings of 2016 Prognostics and System Health Management Conference (PHM-Chengdu) pp. 624-630 (2016)

22. G. Świt, A. Krampikowska, Proceedings of 2016 Prognostics And System Health Management Conference (Phm-Chengdu) pp. 6-11 (2016)

23. G. Świt, A. Adamczak, A. Krampikowska, IOP Conference Series: Materials Science and Engineering 251 (2017)

24. G. Świt, A. Adamczak, A. Krampikowska, IOP Conf. Series: Materials Science and Engineering 245 (2017)

25. M. Clotaire, P. Gueguen, Structural Health Monitoring 9(2) (2009)

26. F. Auger, P. Flandrin, P. Concalves, O. Lenoine, TFTB for Matlab CNRS (1996)

27. J. Adamowski, K. Sun, Journal of Hydrology 390(1-2) (2010) 